\title{
Assessment of Coronary Artery Bypass Graft by Using Multidetector Computed Tomography Coronary Angiography.
}

\author{
Ahmed A. Ibrahim ${ }^{\mathrm{a}}$, Medhat M. Refaat ${ }^{\mathrm{b}}$, Ibrahim M. Helmy ${ }^{\mathrm{c}}$, Yasser M. Abdelhady ${ }^{\mathrm{b}}$
}

a

Department of radiology,

Benha Insurance hospital, Egypt. b department of radiology, Benha faculty of Medicine, Benha University, Egypt, c department of radiology, National heart Institute, Egypt.

Correspondence to: Ahmed A. Ibrahim, department of radiology, Benha Insurance hospital, Egypt

Email:

dr.ahmed_ouf@yahoo.com

Received: 25 July 2019

Accepted: 15 October 2019

\begin{abstract}
:
Background: $\mathrm{CABG}$ surgery is the standard care in the treatment of advanced coronary artery disease. Assessment of the status of the grafts after CABG surgery is an important issue. Recently, MDCT has gained rapid acceptance as a diagnostic cardiac imaging modality, allowing assessment of coronary bypass graft patency with high spatial resolution. Aim: Evaluate the role of (MDCT) in assessment of CABG. Patients and methods: In this prospective study, 30 patients after coronary artery bypass graft surgery are included. The 30 patients were examined by ECG gated MDCT coronary angiography in CT unit in radiology department of national heart institute between (October 2018 to April 2019). Results: The study included 30 patients with prior CABG surgery. Mean age was $61+/-6.9$ years with male gender predominance represented $86 \%$ (26 patients). The evaluable grafts were 75 grafts. The most common used grafts were the venous grafts represented $59 \%$ ( 44 grafts) while arterial grafts represented $41 \%$ (31 grafts).The most common landing site of arterial grafts was LAD (with incidence $84 \%$ ), while the most common landing site of venous grafts was RCA(with incidence 39\%). Conclusion: MDCT coronary angiography is a potentially safe, non-invasive modality in assessment of coronary artery bypass grafts in post-CABG patients.
\end{abstract}

Key words: MDCT, CABG, coronary artery.

List of abbreviations: MDCT: multidetector computed tomography, CABG: coronary artery bypass graft, LAD: left anterior descending artery, LCX: left circumflex artery, PDA: posterior descending artery, OM: obtuse marginal artery, LIMA: left internal mammary artery, SVG: saphenous vein graft. 


\section{Introduction:}

The standard of care for management of advanced coronary artery disease is coronary artery bypass graft (CABG) surgery. The long-term clinical outcome after myocardial revascularization depends on the patency of the coronary artery bypass grafts [1].

However CABGs, similarly to the native coronary vessels may in time, develop stenosis or occlusion [2].

Invasive coronary angiography is the gold standard means of imaging bypass vessels and carries a small but potentially serious risk of local vascular complications, including myocardial infarction, stroke and death [3].

MDCT, compared with invasive coronary angiography, is less expensive, more rapid, less invasive, and may be more accurate for graft imaging than for coronary native arteries because of the relative immobility, the wider luminal diameter, and the lower rate of calcifications [4].

\section{Patients and methods}

\section{Patients:}

In this prospective study, 30 patients after coronary artery bypass graft surgery are included. The 30 patients were examined by ECG gated MDCT coronary angiography in CT unit in radiology department of national heart institute between (October 2018 to April 2019). All examinations were performed by using Dual source 64-sclice MDCT (SIEMENS, SIEMENS medical system,
Germany).The study was approved by the ethics committee of the institute and informed consent was obtained from the patients.

Exclusion criteria include patients with moderate to severe renal insufficiency, patients with history of contrast allergic reaction, patients with heart rate above 85 beat/min who were not responding to medical preparation and patients with severe arrhythmias.

\section{Methods:}

Full clinical and family history was taken from each patient and renal functions were done for all patients before performing the study. The heart rate of patients should be $\leq$ 70 beat/min. patients with heart rate more than 70 beat/min and their $\mathrm{EF}$ was more than $35 \%$ receive short acting selective Bblockers, $10 \mathrm{mg}$ orally $1 \mathrm{~h}$ before the scan. Patient lies supine on the table with head first and ECG leads is putted and connected. Prior to the scan, test was explained to patient and the patient had to practice the breathing instructions that were given during the exam. $130 \mathrm{ml}$ of nonionic lowosmolarity contrast agent that contains 320$350 \mathrm{mg}$ of iodine per millimeter or greater was injected via an antecubital vein using a mechanical double injector. The time of the start of the helical scan after IV contrast administration was determined by Bolus tracking; when we start injection of contrast bolus and give around 10 seconds so 
contrast will reach root of aorta, we asked the patient to take deep breath and start acquisition.

All examinations were performed by using Dual source64-sclice MDCT (SIEMENS, SIEMENS medical system, Germany). Monitoring of electrocardiogram was performed continuously during the examinations, and all image acquisitions were performed during single inspiratory breathhold. An AP and lateral scout acquisition was obtained to determine the position of the heart and define the scan volume for further imaging (from subcarinal level to the diaphragmatic face of the heart).

Multidetector-row helical CT was performed using mainly prospective ECG gating triggering and remolding dose retrospective ECG gating triggering in some cases. In all patients, the standard built in reconstruction algorism was used for image reconstruction. The data sets were reconstructed (with a slice thickness of $0.625 \mathrm{~mm}$ and $0.4 \mathrm{~mm}$ increments) during the mid to end diastolic phase, $45-75 \%$ of the R-R interval. If image quality in this data set was not being optimal, additional reconstructions (35-85\%) was performed and the data sets with optimal images were chosen for further evaluation.

All acquired data was transferred to separate computer workstation .Depending on vessel morphology and quality of the MDCT data sets, different post processing techniques such as MIP, CPR and VR were applied to assess the origin and course of the coronary arteries and bypass grafts. The results were collected, organized and tabulated into a database (Microsoft Excel 2010), and then statistical analysis was performed. The data was analyzed using statistical package for social science (SPSS) version 21 for windows.

\section{RESULTS:}

In this study 30 patients with prior coronary artery bypass graft (CABG) surgery were examined by MDCTA in CT unit in radiology department of national heart institute between (October 2018 to April 2019). Mean age was $61+/-6.9$ years with male gender predominance represented 86 $\%$ (26 patients).

The evaluable grafts were 75 grafts. The most common used grafts were the venous grafts represented $59 \%$ (44 grafts) while arterial grafts represented $41 \%$ (31 grafts).The most common landing site of venous grafts was RCA (with incidence 39\%), followed by OM (with incidence 35\%), then PDA (with incidence $12 \%$ ), diagonal artery (with incidence 9\%) and LAD (with incidence 5\%) (Fig.1).

The most common landing site of arterial grafts was LAD (with incidence 84\%), followed by diagonal artery (with incidence 10\%), then LCX (with incidence 6\%) (Fig.2). Regarding the patency of arterial grafts; (88\%) were patent, $(6 \%)$ were significantly narrowed, and $(6 \%)$ were occluded. Regarding the patency of venous grafts ; $(59 \%)$ were seen patent, (11\%) 
were seen significantly narrowed, $(7 \%)$ were seen non-significantly narrowed, and (23\%) were seen totally occluded (table 1).

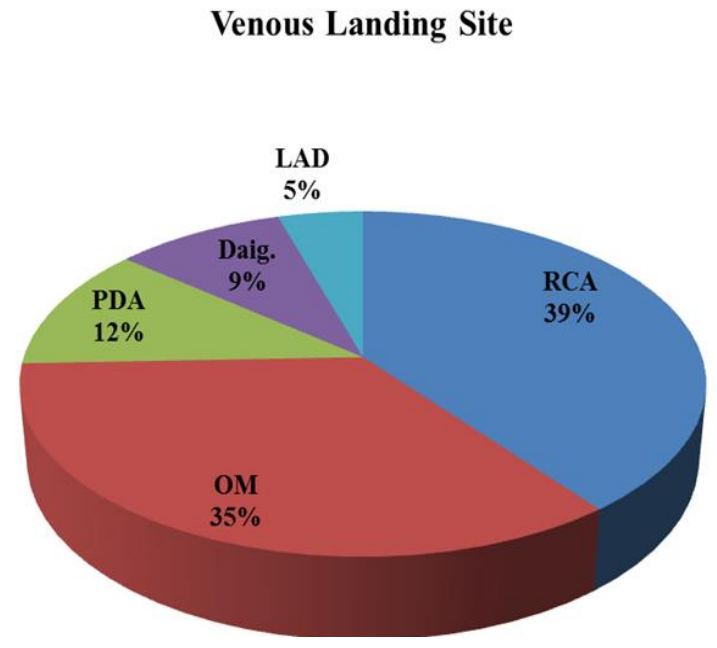

Figure (1): Showing incidence of landing sites of venous grafts.

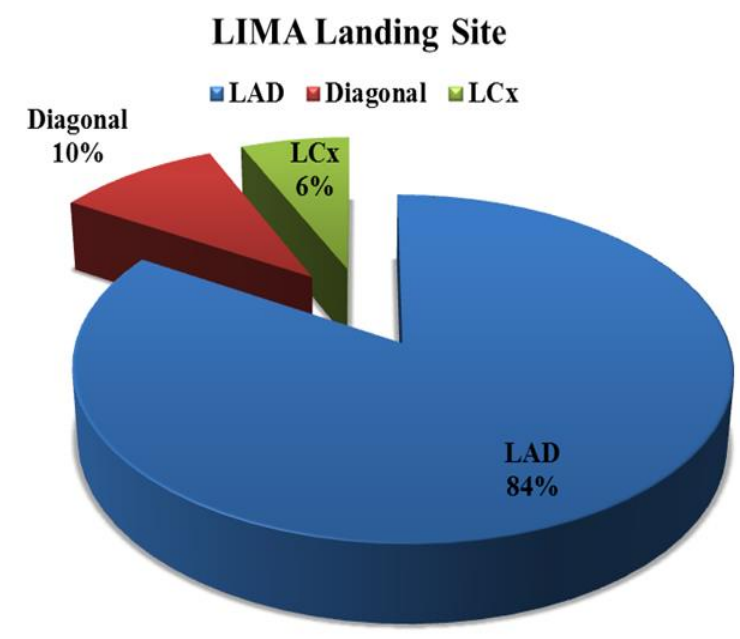

Figure (2): showing incidence of landing sites of left internal mammary artery (LIMA) grafts to the native coronary artery.
Table 1: incidence of landing site and patency of arterial and venous grafts.

\begin{tabular}{|l|l|l|}
\hline & Venous grafts & Arterial grafts \\
\hline $\begin{array}{l}\text { Incidence of } \\
\text { landing site }\end{array}$ & $\begin{array}{l}\text { 1) To RCA (39\%) } \\
\text { 2) To OM (35\%) } \\
\text { 3) To PDA (12\%) }\end{array}$ & $\begin{array}{l}\text { 1) To LAD (84\%) } \\
\text { To diagonal } \\
\text { artery (10\%) }\end{array}$ \\
& $\begin{array}{l}\text { 4) To diagonal } \\
\text { artery (9\%) }\end{array}$ & 3) To LCX (6\%) \\
& 5) To LAD (5\%) & \\
\hline patency & 1) Patent (59\%) & 1) Patent (88\%) \\
& 2) Significantly & 2) Significantly \\
narrowed (11\%) & narrowed (6\%) \\
& 3) $\begin{array}{l}\text { Non- } \\
\text { significantly } \\
\text { narrowed (7\%) }\end{array}$ & Occluded (6\%) \\
& 4) Occluded (23\%) & \\
\hline
\end{tabular}

DISCUSSION:

The postoperative assessment of bypass conduits and anastomosis after CABG is important in order to evaluate surgical results. Until recently, selective bypass graft angiography has been considered the gold standard for the evaluation of early and late bypass patency, but it is invasive and carries risks of such serious complications as myocardial infarctions, embolic events, graft dissections, arrhythmias, and strokes [5].

Venous grafts have demonstrated a tendency to develop partial or complete occlusions with time, whereas arterial grafts have shown relative resistance to plaque formation and obstruction. However, arterial conduits are more limited in their availability and ease of procurement compared with venous grafts, specifically the saphenous vein. Therefore, saphenous vein grafts (SVGs) 
remain the most commonly used conduits for coronary artery bypass surgery [6].

In this study, venous grafts were the most common type of grafts. It represented 44 out of 75 grafts (about 59\%).In this study, MDCT angiography showed that 26 of the venous grafts (59\%) were patent; 5 (11\%) were significantly narrowed; 3 (7\%) were non significantly narrowed and $10(23 \%)$ were totally occluded. This gave a rate of complications of about $41 \%$ considering that the mean time after operation was 5 years \pm 2 years which was near to results of Grondin et al., 1989 who stated that for venous coronary artery bypass grafts, an occlusion rate of $12 \%$ $-20 \%$ was estimated in the first year postCABG, with $2 \%-4 \%$ annual occlusion rates for the next four or five years [7].Also our results were near to that of Risteski et al., 2006 who found that after 10 years, occlusion rates of about $60-70 \%$ have been reported for venous grafts [8].

The RCA was the commonest site for venous graft landing (39\%) (Fig.3), followed by OM artery (35\%), diagonal artery (9\%).PDA (12\%) and LAD (5\%). These findings were near to findings of Houslay et al., 2007 as landing sites of venous grafts in their study were to RCA in $32.5 \%$; to the $\mathrm{OM}$ in $33.8 \%$; to the PDA in $8 \%$; and to the diagonal artery in $9 \%$ of their venous grafts[3].

As regard the arterial grafts, they represented $41 \%$ (31 out of 75 ) of the evaluable grafts in this study.

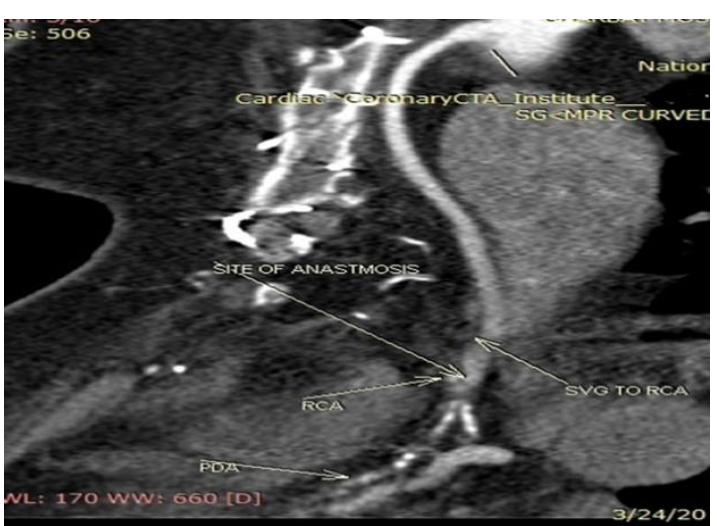

Figure (3): Curved MPR image shows patent SVG to right coronary artery (RCA).

MDCT angiography demonstrated that for LIMA grafts; 27 (88\%) of them were patent, $2(6 \%)$ were significantly narrowed, and 2 $(6 \%)$ were totally occluded. The LIMA grafts showed an $88 \%$ rate of patency in our study compared to $90 \%$ rate of patency according to Flohr et al., 2005[9].Also this gave a rate of complications of about $12 \%$ which was near to the results of Khot et al., 2004 as the occlusion rate in arterial grafts in their study was about $10 \%[10]$.

The LAD artery is the most common site for landing of the LIMA graft as (Fig.4), it is the most important coronary artery branch supplying the left ventricle and due to other anatomical considerations as they are both anteriorly located in the chest. $84 \%$ of LIMA grafts in this study were connected to LAD artery, $6 \%$ of them were connected to LCX artery and $10 \%$ of them were connected to diagonal artery. These findings were near to findings of Houslay et al., 2007 as $86 \%$ of their LIMA grafts were connected to LAD 
artery, while about $4 \%$ of them were connected to LCX artery [3].

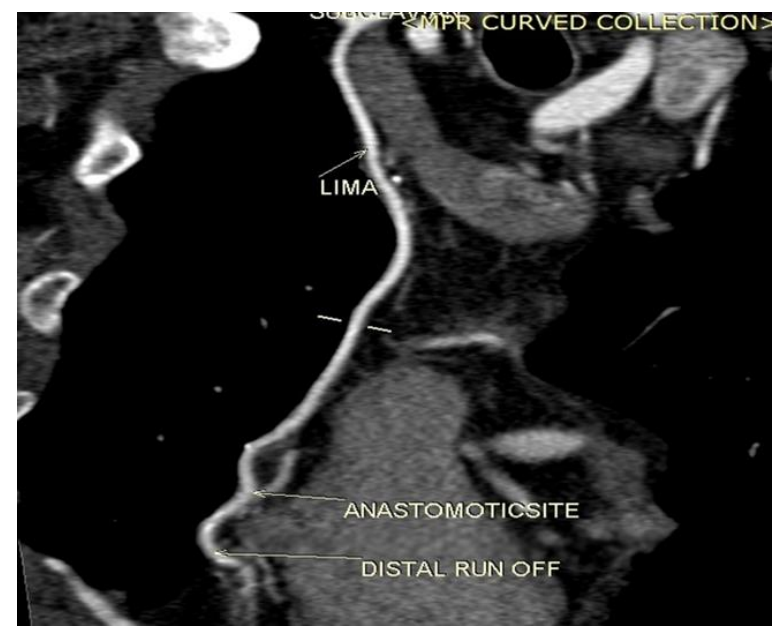

Figure (4): Curved MPR image shows patent LIMA to LAD with good opacification of its anastomotic site and good distal run off.

In this study, all the used in situ arterial grafts were LIMA grafts. They showed $88 \%$ rate of patency compared to about $90 \%$ rate of long term patency according to Risteski et al., 2006[8].

Also in this study there was $6 \%$ rate of significant narrowing and $6 \%$ rate of totally occluded which agreed with the findings of Khot et al., 2004 who stated that LIMA bypass grafts had late occlusion rate of $9.6 \%$ post implantation[10].

The LIMA grafts are usually closely related to a lot of surrounding surgical clips that may make them non-evaluable. However in this study almost all grafts were evaluated due to high resolution, the quality of the contrast and the use of dual-source MDCT. Saphenous vein grafts are less susceptible to this problem; mainly due to their larger caliber and the less usage of surgical clips around them.

Thin slab maximum intensity projection (MIP) allowed better assessment by visualization of the extended lengths of the grafts at once. In the presence of calcium or metal, multi-planner reconstructions (MPR); especially the curved planes were suitable for better assessment. Volume rendering (VR) reconstructions were used for three dimensional orientations and global presentation of results.

\section{Conclusion:}

It is widely accepted that myocardial surgical revascularization with coronary artery bypass grafts is an effective method for eliminating angina. Furthermore, this kind of surgery also improves life expectancy in patients with severe coronary disease.

At coronary artery bypass graft (CABG) surgery various conduits are used and could be divided into arterial and venous grafts. Venous grafts have demonstrated a tendency to develop partial or complete occlusions with time, whereas arterial grafts have shown relative resistance to plaque formation and obstruction. However, arterial conduits are more limited in their availability and ease of procurement compared with venous grafts, especially the saphenous vein. Therefore saphenous vein grafts (SVGs) remain the most commonly used conduits. So the 
occurrence of CABG disease and occlusion is common and increases over the years.

The gold standard to evaluate coronary artery bypass graft (CABG) after coronary revascularization is the conventional coronary angiography. However, coronary angiography is invasive and expensive, and it carries procedure-related risks.

MDCT is less risky than coronary angiography, and has good image quality due to short scanning time and slice thickening, and it is faster than other noninvasive methods.

Technical improvements in Multi-detector computed tomography have enabled this technique to be used for monitoring patency after CABG. With the improved spatial and temporal resolution of new generations of MDCT $(64,128,256 \ldots .$.$) , assessment of the$ distal anastomosis sites, as well as evaluation of severely calcified coronary arteries was made possible with greater accuracy.

\section{References:}

1- Harskamp RE, Alexander JH, Ferguson TB Jr, Hager R, Mack MJ, Englum B, et al. Frequency and Predictors of Internal Mammary Artery Graft Failure and Subsequent Clinical Outcomes: Insights From the PREVENT IV Trial. Circulation.2016; 133:131-8.

2- Ascarelli A, Francone M, Cannata D, Cannavale A, Carbone L, Passariello R. Role of multidetector CT in the evaluation of coronary artery bypass grafts. Imaging Med 2010; 2:77-86.

3- Houslay ES, Lawton T, Sengupta A, Uren NG, McKillop G, Newby DE. Non-invasive assessment of coronary artery bypass graft patency using 16slice computed tomography angiography. J Cardiothoracic Surg. 2007; 2:27.

4- Di Lazzaro D, Crusco F. CT angio for the evaluation of graft patency. J Thorac Dis 2017; 9:283-8.

5- Mannacio VA, Imbriaco M, Iesu S, Giordano AL, Di Tommaso L, Vosa C. 64-slice multidetector computed tomographic evaluation of arterial conduit patency after off-pump coronary artery bypass grafting. Tex Heart Inst J. 2009; 36:409415.

6- Frazier A., Qureshi F., Read K., Gilkeson R.C., Poston R.S., White C.S. Coronary artery bypass grafts: assessment with multidetector $\mathrm{CT}$ in the early and late postoperative settings. Radiographics. 2005; 25:881-896.

7- Grondin CM, Campeau L, Thornton JC, Engle JC, Cross FS, Schreiber H. Coronary artery bypass grafting with saphenous vein. Circulation 1989; 79:I24-9.

8- Risteski PS, Akbulut B, Moritz A, Aybek T. The radial artery as a conduit for coronary artery bypass grafting: review of current knowledge. Anatol J Cardiol. 2006; 6:153-62.

9- Flohr TG, Schaller S, Stierstorfer K, Bruder H, Ohnesorge BM, Schoepf UJ. Multi-detector row CT systems and image-reconstruction techniques. Radiology. 2005; 235:756-773.

10- Khot UN, Friedman DT, Pettersson G, Smedira NG, Li J, Ellis SG. Radial artery bypass grafts have an increased occurrence of angiographically severe stenosis and occlusion compared with left internal mammary arteries and saphenous vein grafts. Circulation. 2004; 109:2086-2091.

To cite this article: Ahmed A. Ibrahim, Medhat M. Refaat, Ibrahim M. Helmy, Yasser M. Abdelhady, assessment of coronary artery bypass graft by using multidetector computed tomography coronary angiography, BMFJ. 2020; 37(2):347-353. DOI: 10.21608/bmfj.2020.15259.1026 